\title{
Design and Analysis of a Tension Leg Platform's Column for Arabian Sea
}

Latif $U$ * and Naeem Shah A

Department of Mechanical Engineering, University of Engineering and Technology, Lahore 54000, Pakistan

\begin{abstract}
Offshore structures such as boats, ships, oil rigs etc. are under continuous wave loading. These waves exert pressure on the structure which in turn produces stresses in them. These waves can strike structure from any direction and it is very difficult to calculate the pressure exerted by the waves analytically as the shape of the offshore structures is rather complex. The pressures and associated stresses and buckling caused by the striking waves are harmful to the structure, and may lead to their failure. Keeping in view the above scenarios, the column of an offshore oil platform was designed on the basis of hurricane's history of Arabian Sea. The normal and worst sea environment conditions were kept in mind while designing the column and its subsequent analysis was made on the basis of stress and buckling in this study. After analyzing the structure, it is known that the offshore column design is safe for particular sea state. The factor of safety (fos) was 1.90 and 1.77 for the normal and worst conditions, respectively. The pressure was decreased with the increase in wave frequency, while increased with the increase in wave amplitude. Further, buckling modes of extraction were in the range of 1.23 to 1.59 .
\end{abstract}

Keywords: Buckling; Offshore; Pressure; Sea state; Stress; TLP

\section{Introduction}

According to latest surveys made for the exploration and exploitation of the oil reserves, it is estimated that deep water oil reserves are in abundance as compared to the existing land reserves Mallory [1]. Therefore, an intensive study along with practical application has been focused on offshore structures in recent times. Offshore structures remain under continuous wave loading during their service or operational life. The life time span of an offshore oil rig is commonly between 25 to 40 years Arvid and Moan [2].

Offshore structures are used by oil and gas industries like Shell Pvt. Ltd. for extraction of natural resources in the marine environment. The most suitable type of offshore structures for intermediate and higher depths is Tension Leg Platform (TLP) Chakrabarti [3]. This Type of offshore structure mostly selected due to its higher stability in harsh sea environment as compared to other offshore structures.

A critical component of the TLP is its column which needs to be modeled with care so that platform may perform its operation smoothly and maintain its stability in the harsh sea environment. Different Types of waves like regular, irregular, long crested and short crested waves strike with the offshore oil rigs column and causes the loading/pressure on it.

The environment for which offshore engineers are designing a column can be hostile, so the constraints and safety measures which govern the design are very crucial parameters. In current study, a TLP column was designed for the particular Sea State on the basis of the history of cyclones which have been encountered in the Arabian Sea so far. The main focus of the study is on the design and analysis of the column of offshore oil rig/platform against stresses and buckling. Two different failure modes are addressed in this paper.

\section{Factors/Data Involved in the Design and Analysis}

As the strong evidence of the existence of hydrocarbon/Oil and Gas resources in Pakistani Sea and therefore some research activities related to this field have been reported in the near past, so the TLP column was designed on the basis of hurricanes data available in the literature. This is expected to be helpful in the exploration of the Oil and Gas from the specified location like Costal Area of Makran in Pakistan.

\section{Hydrocarbon resources availability}

Offshore regions of Pakistan have thick marine sedimentary reservoir rocks with potential traps both structural and stratigraphic Nuzhat [4]. All the prerequisites of oil and gas occurrence i.e. source; reservoir and traps are amply present in the offshore basins of Pakistan. Many seismically delineated anticlinal traps are available for exploration. Deltas, their fans and cones are favorable locations for oil and gas accumulation. The Indus delta and Indus offshore areas have proved to be a major hydrocarbon producing area. In the deltaic region, exploration activities have identified many promising fields Nuzhat [4]. A large number of untested anticlinal structures have been seismically delineated in the Balochistan offshore area. Surface features such as oil seepages and mud volcanoes show the generation of hydrocarbons in the area. Gas deposits (mostly methane) are common along the Makran coast Nuzhat [4]. Offshore Makran has shown good quality reservoir rock. From the Makran continental margin gas hydrates can be extracted as another source of energy that has been discovered recently Nuzhat [4].

\section{Hurricanes data (encountered in Arabian Sea)}

The Indian Ocean is considered among the largest oceans of the world and it is at number three in the list of largest oceans of the world. Arabian Sea is the northwestern part of this ocean. Indian Ocean is included in the oceans of the world which have the hot environment or higher temperature as compared to the other oceans of the world. Gulfs and countries which are situated along with the Arabian Sea are Gulf of Aden and Gulf of Oman and Pakistan, India, Maldives, Sri Lanka and

*Corresponding author: Latif U, Department of Mechanical Engineering, University of Engineering and Technology, Lahore 54000, Pakistan, Tel: 0092-3226029770; E-mail: usman_mechanical@yahoo.com

Received April 21, 2016; Accepted May 18, 2016; Published May 22, 2016

Citation: Latif U, Naeem Shah A (2016) Design and Analysis of a Tension Leg Platform's Column for Arabian Sea. J Appl Mech Eng 5: 218. doi:10.4172/21689873.1000218

Copyright: ( $) 2016$ Latif U, et al. This is an open-access article distributed under the terms of the Creative Commons Attribution License, which permits unrestricted use, distribution, and reproduction in any medium, provided the original author and source are credited. 
Citation: Latif U, Naeem Shah A (2016) Design and Analysis of a Tension Leg Platform's Column for Arabian Sea. J Appl Mech Eng 5: 218. doi:10.4172/2168-9873.1000218

Somalia. The Arabian Sea has the ability to generate cyclones but the storms are very infrequent in this part of the ocean. Most prominent examples of cyclones are "Gonu" and "Phet" Hussain [5]. Total 50 numbers of cyclones has been observed in this sea since 1890 to 2013 Hussain [5].

\section{Description of the Model}

The TLP column is made of HY-80 Alloy Steel. The reason behind the selection of this material is its higher resistance power against the corrosion. We know that the sea water is brackish water due to which corrosion rate of every material increases in sea water as compared to land use. The corrosion rate of HY-80 alloy steel is 2-3MPY Dexter [6]. The detailed description of the column is given in the Table 1.

Ideally, the model should be as large as it can be, so that the scaling effect and errors can be reduced or kept to a minimum level. Scaling effect is commonly involved when it is required to make the prototype of the model to test it in the lab. But in this case, authors performed the analysis with the help of different softwares. Authors have used the true dimensions of the column and thus calculated the true and complete effects/impacts of the wave loading on the column (Figure 1).

\section{Hydrodynamic Analysis in Frequency Domain Using ANSYS AQWA}

ANSYS AQWA software addresses the vast majority of analysis requirements associated with hydrodynamic assessment of all types of offshore and marine structures like SPARs, Ships, FPSOs, Semisubmersibles, Break Waters and Tension Leg Platform [I]. ANSYS AQWA Diffraction provides an integrated facility for developing

\begin{tabular}{|c|c|}
\hline Description & Value \\
\hline Volume & $29897.5 \mathrm{~m}^{3}$ \\
\hline Ixx & $1.05109 \mathrm{~kg} \cdot \mathrm{m}^{2}$ \\
\hline Iyy & $1.05109 \mathrm{~kg} \cdot \mathrm{m}^{2}$ \\
\hline Izz & $1.98108 \mathrm{~kg} \cdot \mathrm{m}^{2}$ \\
\hline VCB & $17.50 \mathrm{~m}$ \\
\hline Center of Gravity From Bottom & $18.54 \mathrm{~m}$ \\
\hline Total upward thrust & $161885.79 \mathrm{kN}$ \\
\hline Draft & $35 \mathrm{~m}$ \\
\hline Free Board & $30 \mathrm{~m}$ \\
\hline Dia of the Column & $24.2 \mathrm{~m}$ \\
\hline Design Wave Height for Normal Sea Environment & $2 \mathrm{~m}$ \\
\hline Design Wave Height for Normal Sea Environment & $7 \mathrm{~m}$ \\
\hline
\end{tabular}

Table 1: Detail of column.

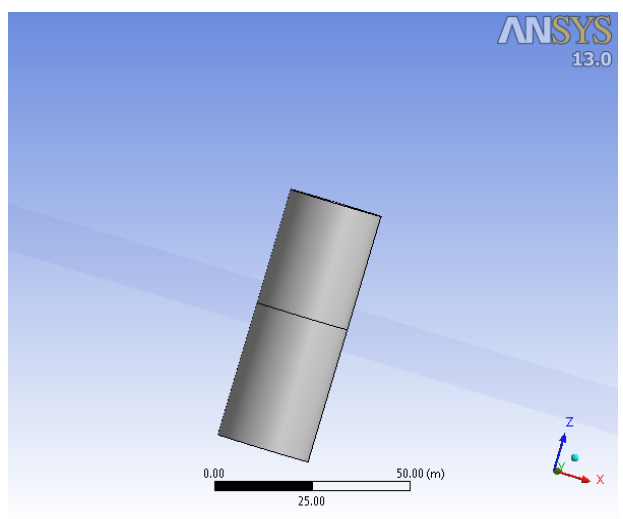

Figure 1: Column of TLP. primary hydrodynamic parameters required to undertake complex motions and response analysis. Hydrodynamic analysis results, such as motions and pressures, can be transferred to ANSYS structural mechanics products, ANSYS ASAS or generically defined FE models for subsequent structural analysis [I].

ANSYS AQWA Suite extends ANSYS AQWA Diffraction to include analysis capabilities for global performance of moored and connected systems subject to random sea states. Simulations may be static or dynamic in frequency and in time domain [I].

\section{Pressure mapping}

The pressure mapping is a process or method which enables to define the parameters in one specific software and then import the results or text into software. The pressure mapping was performed by using ANSYS ASAS, ANSYS AQWA WAVE and Load Case File. ANSYS AQWA Wave software may be used to investigate the effects of currents, waves and wind on fixed or floating offshore and marine structures including Floating Production Storage and Offloading unit, Spars, TLP, Semi-Submersible units, ships etc. ANSYS Inc. [7].

\section{Von misses criteria for the investigation of stresses}

Von Misses criterion is used to check whether the design is safe or not against the applied stresses. A complex three dimensional system of stresses is developed by applying load (pressure) on a body in three dimensions. Magnitude and direction of stresses are changed at every point within a body. The failure of a structure at a given point thus can be calculated by using Von Misses criterion given as follows [II]:

$$
(\mathrm{S} 1-\mathrm{S} 2)^{2}+(\mathrm{S} 2-\mathrm{S} 3)^{2}+(\mathrm{S} 3-\mathrm{S} 1)^{2}=2 \mathrm{~S}_{\mathrm{e}}{ }^{2}
$$

Where S1, S2 and S3 are the principal stresses and Se is the equivalent stress or "Von Misses Stress".

\section{Block LANCZOS method for buckling analysis}

Block LANCZOS method is an iterative method used to find the different modes of extraction of eigen buckling in ANSYS APDL Mechanical. As it is an iterative method so it performs iterations till the exact values are obtained.

\section{Results and Discussion \\ Effect of wave frequency on pressure}

Figure 2 shows the effect of different wave frequencies on the pressure applied on the column. It is clear that there is an inverse relationship between frequency and applied pressure on the column. As the value of frequency of the wave increases, the applied pressure decreases.

As we know that, frequency is the number of cycles per unit time. So, if the value of frequency increases it means that number of cycles per unit time also increases. As the number of cycles increases in a unit time then the height of the wave decreases and a wave of smaller amplitude strikes with the structure which in turn produces smaller pressure on the structure. This is the reason for the decrease in pressure as the frequency is increased.

\section{Effect of wave amplitude on pressure}

Analysis was also carried out for the impact of different wave amplitudes on the pressure applied to the column as shown in Figure 3. It is obvious that there is a linear relationship between amplitude and 
Citation: Latif U, Naeem Shah A (2016) Design and Analysis of a Tension Leg Platform's Column for Arabian Sea. J Appl Mech Eng 5: 218. doi:10.4172/2168-9873.1000218

Page 3 of 5

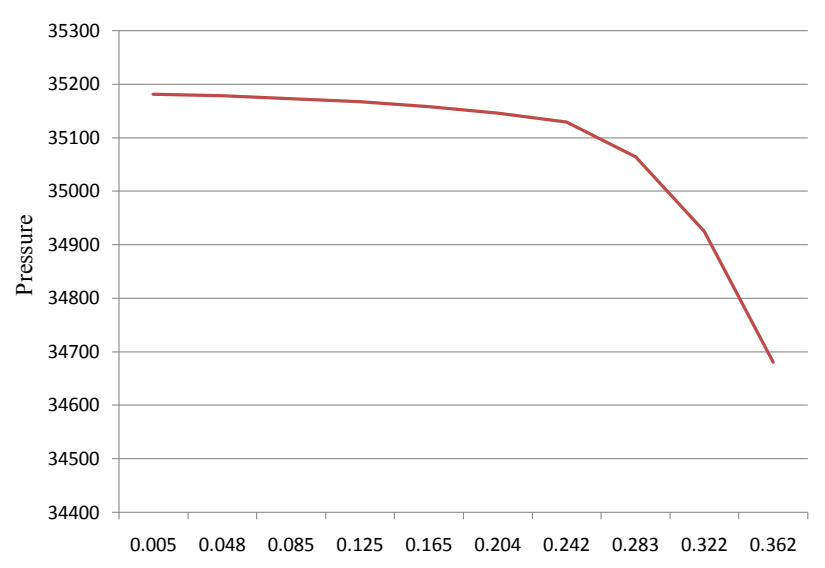

Figure 2: The relationship between wave frequency and column pressure.

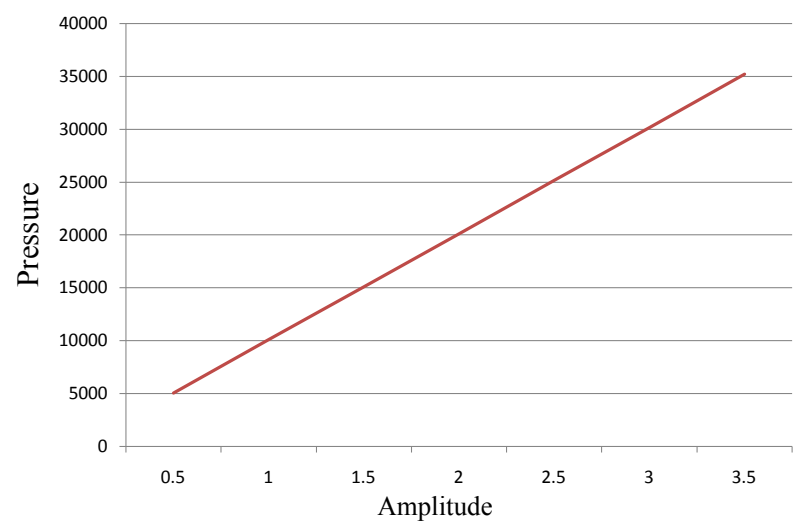

Figure 3: The relationship between wave amplitude and column pressure.

pressure of the waves. As the value of amplitude increases the pressure of the wave on offshore oil rig/TLP column also increases.

The increase in pressure is attributed to the height of the wave. As the wave height increases, the energy or disturbing potential of the wave is also increased. Wave is not a motion of water rather it is the transfer of disturbance from one particle to another particle. Thus, the wave with higher amplitude possesses the higher energy which creates greater pressure on the column as compared to that with lower amplitude.

\section{Analytical verification of pressure mapping}

As discussed above a load case file is to be generated/developed to transfer the pressures generated by waves on the column from one software i.e. ANSYS AQWA Lin to another software i.e. ANSYS APDL Mechanical. A load case file was developed in this study along with the summary/entries given as follows:

System Data Area 200000

JOB NEW LINE

PROJECT ANSY

EXTENSION dat

END Model. asas

END AQWAID Analysis stat

\section{FELM}

\section{FEPG ANSY}

END LOAD CASE

07520

\section{END STOP}

The pressure mapping output file is given in Figure 4.

Analytical verification of hydrostatic pressure mapping is performed using the following expression Journee and Massie [8]:

$$
\mathrm{P}_{\max }=\rho \mathrm{gh}+\rho \mathrm{g} \zeta^{\left(-\mathrm{k}^{*} \mathrm{z}\right)}
$$

where,

$\mathrm{P}_{\max }=$ Maximum value of pressure at any node/element.

$\rho=$ Density of Sea Water

$\mathrm{g}=$ Gravitational Acceleration

$\mathrm{h} / \mathrm{z}=$ Depth/Length of Column in Sea Water

$\zeta=$ Amplitude

$\mathrm{k}=$ Wave Number

Now by putting these values in the above equation we get:

$=351933.75 \mathrm{~Pa}$

The analytically calculated pressure value is compared with that computed with the software, as shown in Figure 4. So it is found that pressure mapping is quite right.

\section{Stresses and buckling analysis}

After analysis in ANSYS Mechanical APDL, the maximum value for Von Misses stresses at wave height $2.0 \mathrm{~m}$ and $7.0 \mathrm{~m}$ were obtained as shown in Figures $5 \mathrm{a}$ and $5 \mathrm{~b}$ ) which are $291 \mathrm{MPa}$ and $312 \mathrm{MPa}$, respectively.

When a structural member is subjected to an axial compressive load, it may fail by a condition called BUCKLING. Buckling is not so much a failure of the material (as is yielding and fracture), but an instability caused by system geometry American Bureau of Shipping [8].

The results for the buckling analysis are shown in Figure 6. Buckling analysis shows the results for five modes of extraction which are ranging from 1.23 to 1.59 . The value of frequency obtained by analysis is 1.23 as shown in Fig. 6 at serial number 1, which represents a safe design. If the value of frequency becomes less than one then it will be an unsafe design or buckling may lead the designed column towards collapse/ failure. The value of frequency greater than one is the description of safe

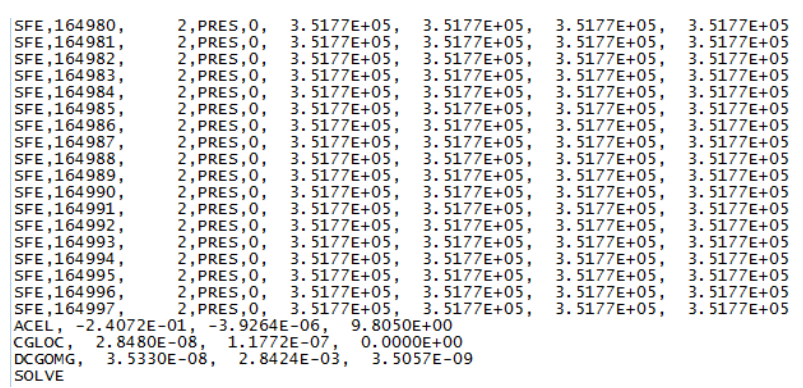

Figure 4: Pressure values at different points/nodes. 
Citation: Latif U, Naeem Shah A (2016) Design and Analysis of a Tension Leg Platform's Column for Arabian Sea. J Appl Mech Eng 5: 218. doi:10.4172/2168-9873.1000218

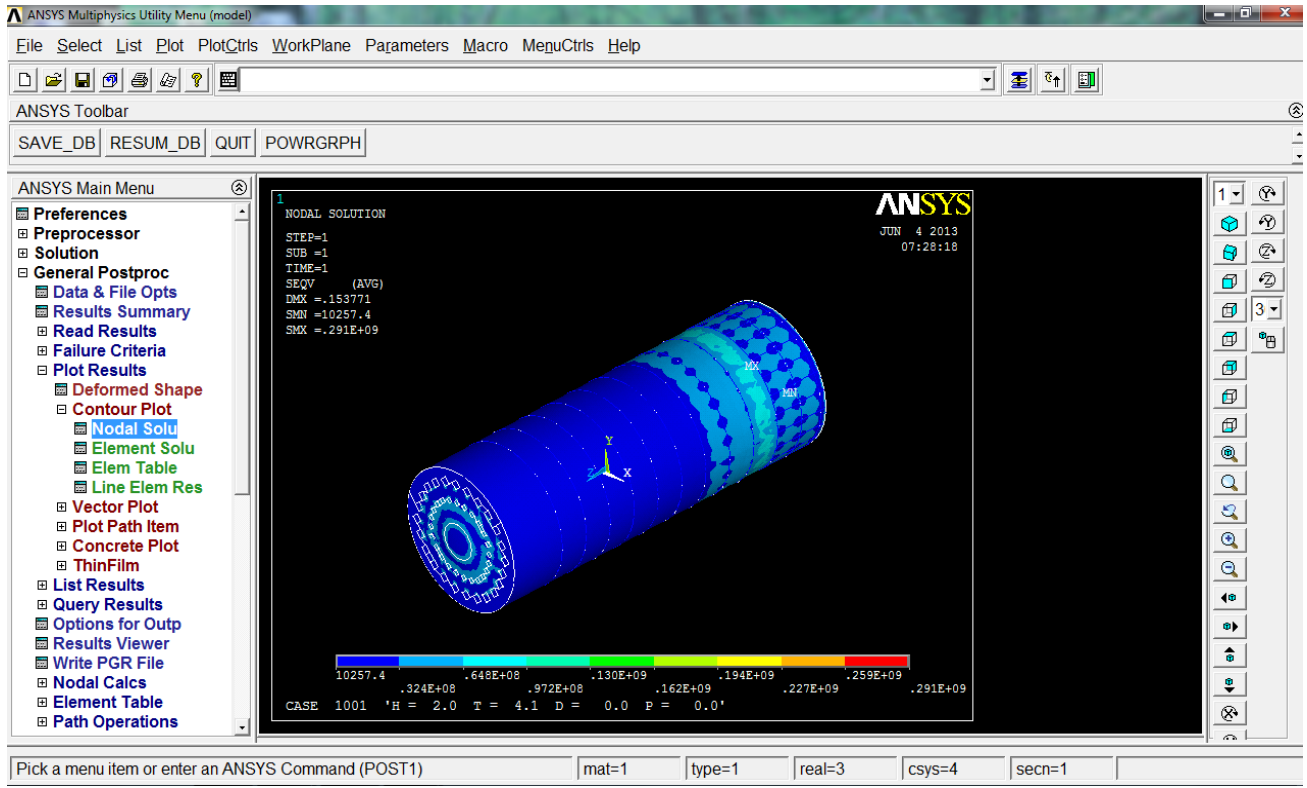

Figure 5a: Von Misses stresses at wave height $2.0 \mathrm{~m}$.

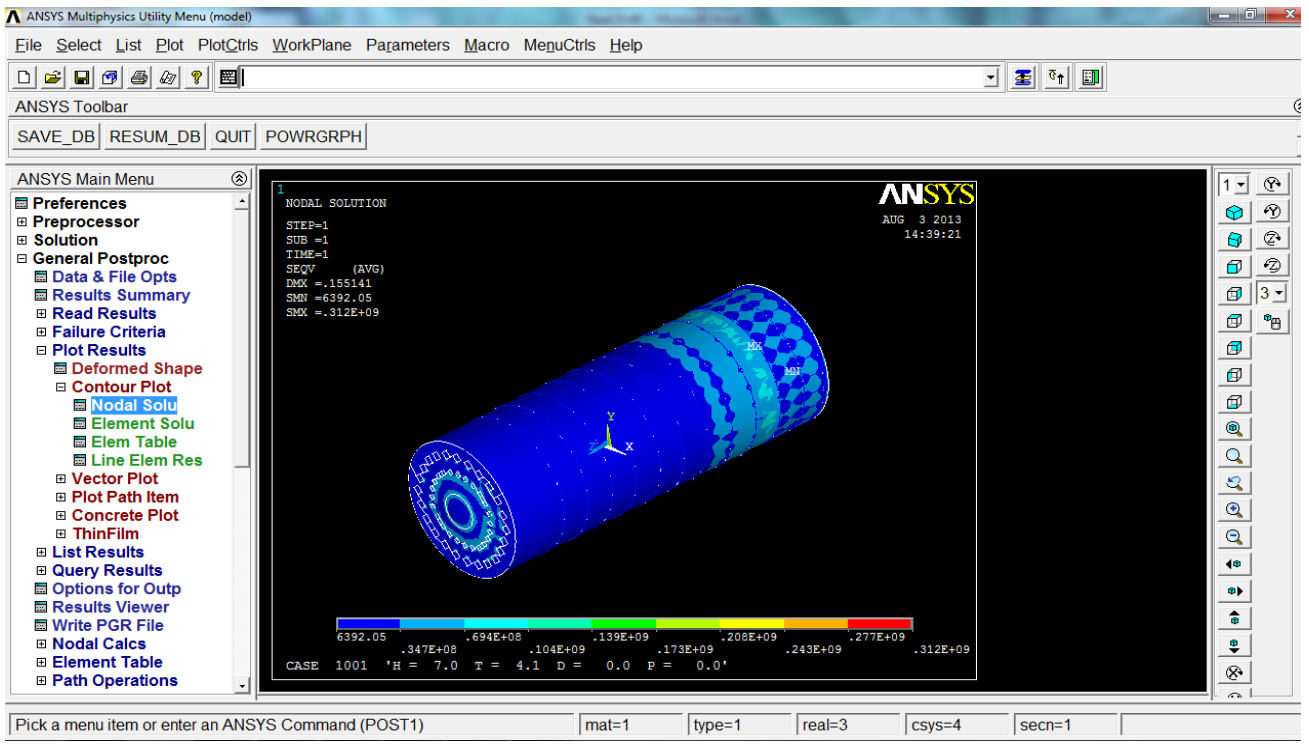

Figure 5b: Von Misses stresses at wave height $7.0 \mathrm{~m}$.

design regarding buckling (here frequency represents the critical load). This value is also greater than the set standards of ASME. According to ASME the value of frequency or critical load should be 1.2 or more.

The designed offshore column must fulfill the following condition to show its safe design.

$$
\begin{aligned}
& \mathrm{R}>\mathrm{Q} \\
& \text { Where, } \\
& \mathrm{R}=\text { Column's Strength } \\
& \mathrm{Q}=\text { Applied load on the Column }
\end{aligned}
$$

\section{$\mathrm{R}=$ Column's Strength}

Above mentioned equation could be given in terms of the total factor of safety " $\gamma$ ", as follows Shama [9]

$$
\gamma=\mathrm{R} / \mathrm{Q}>1.0
$$

As discussed earlier that the highest wave encountered in Arabian/ Pakistani Sea was of height 16-20 feet but the current model/column was analyzed for worst condition in which waves may have the height up to 23 feet.

After Analysis it was found that the column of offshore oil rig/ Tension Leg Platform is quiet safe with respect to the Arabian Sea's working environment and conditions $[10,11]$.

The cyclones which encountered at Pakistani Coastal Area were kept in mind while designing the offshore column. Generally, a Von Misses criterion is applicable to check or verify the structural safety or failure. After the evaluation of all kinds of results, the factor of safety 
Citation: Latif U, Naeem Shah A (2016) Design and Analysis of a Tension Leg Platform's Column for Arabian Sea. J Appl Mech Eng 5: 218. doi:10.4172/2168-9873.1000218

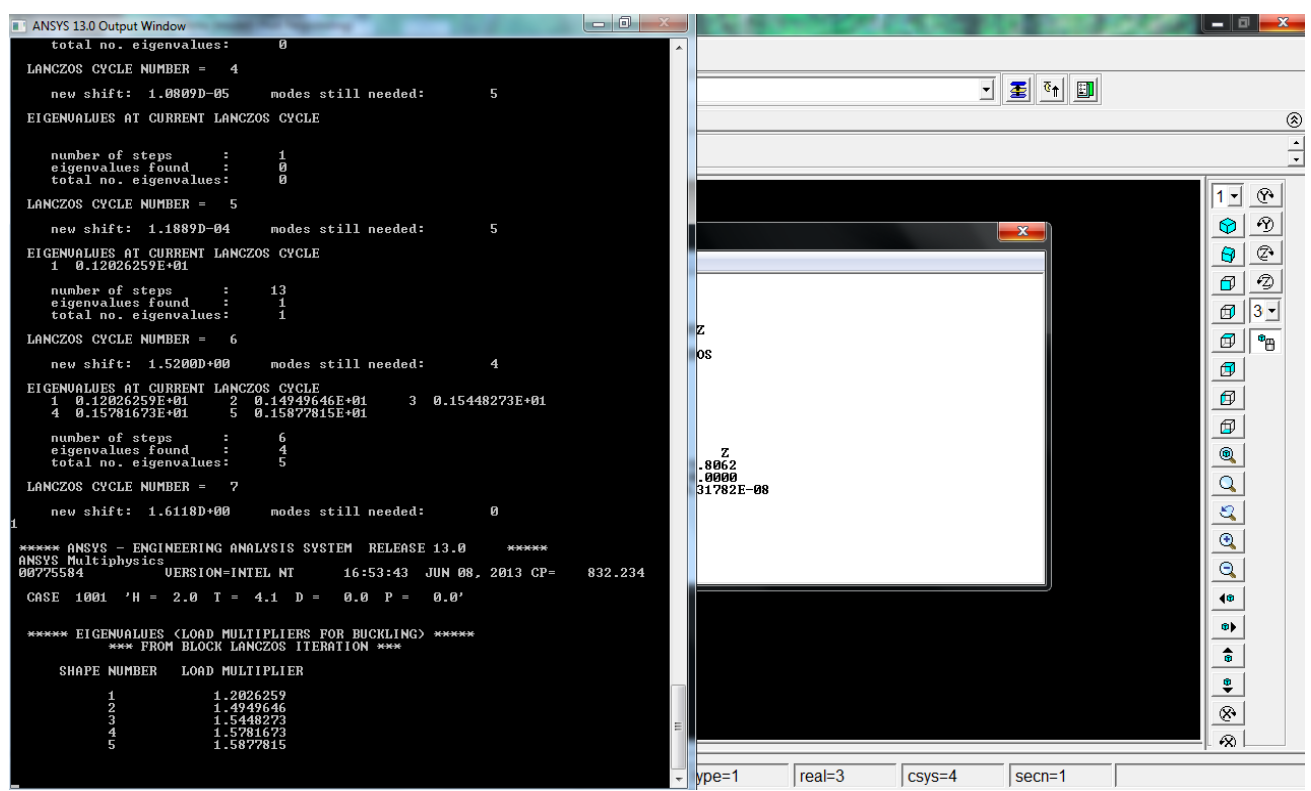

Figure 6: Solution of buckling analysis (output window).

obtained in normal and worst Sea environment/conditions are as under:

Applied Stresses under Von Misses Criteria at Wave Height $2.0 \mathrm{~m}$ $=291 \mathrm{M} \mathrm{Pa}$

Applied Stresses under Von Misses Criteria at Wave Height 7.0 m $=312 \mathrm{M} \mathrm{Pa}$

\section{Material Ultimate Strength $=552 \mathrm{M} \mathrm{Pa}$}

Factor of Safety under Von Misses Stress=1.90 Approx. (at Wave Height $2.0 \mathrm{~m}$ )

Factor of Safety under Von Misses Stress=1.77 Approx. (at Wave Height $7.0 \mathrm{~m}$ )

\section{Buckling Frequency/Critical Load=1.23-1.59}

Safety factor is of prime importance in the designs where the loss of human lives is expected or involved. In present case there is a danger of wastage of human lives. This is the reason for the factor of safety to be taken more than 1.5 , which is however 1.77 in this study.

\section{Conclusion}

Current study is focused on the design and analysis of a TLP column that needs to be designed with some extra supports to reduce the effect of stress concentration and to sustain against the unusual sudden impacts of slamming, wave and current loading. The results show that the pressure on the structure decreases as the wave frequency is increased, while increases with the increase in wave amplitude. It was found that the designed column is safe with respect to ultimate stress and buckling phenomenon even in the true and worst hurricane conditions. From the history of Arabian Sea, it is revealed that the cyclones encountered at 18-20 ft wave height, however the designed column was analyzed on the basis of a wave height up to $23 \mathrm{ft}$. After analysis, it was found that the structure is safe with a factor of 1.90 and 1.77 for normal and worst conditions, respectively. Moreover, buckling modes of extraction were in the limit of 1.23 and 1.6 which are also safe with the view point of the ASME standards.

\section{Recommendations}

The designed column is safe for practical use and may be implemented in Pakistani/Arabian Sea in the Makran Coastal Area where Oil and Gas reserves are frequently available.

\section{References}

1. Mallory (2010) Deep water Gulf of Mexico oil reserves and production.

2. Arvid N, Moan T (2005) Probabilistic design of offshore structures. Chakrabarti Hand Book of offshore Engineering, Elsevier Oxford: 191-272.

3. Chakrabarti S (2005) Hand book of offshore engineering Elsevier USA.

4. Nuzhat K (2011) Marine resources in Pakistan: A tentative inventory. Pakistan Business Review 12: 837-838.

5. Hussain MB (2011) Pakistan weather portal.

6. Dexter SC (1972) Hand book of oceanographic engineering materials Metals and Alloys: 62-63.

7. ANSYS Inc. (2010) AQWA wave user Manual Hydrodynamic Load Transfer 1-90.

8. American Bureau of Shipping (2005) Buckling and ultimate strength assessment for offshore structures: Commentary Guide: 1-151.

9. Shama MA (2009) Basic concept of the factor of safety in marine structures 4: $307-314$

10. Ansys (2015) Realize your product promise-Explore Engineering Simulation.

11. Von Mises Stress-Von Mises-Hencky criterion for ductile failure. 